\title{
An latrogenic Femoral Artery Pseudoaneurysm Caused by Endovascular Stenting for the Treatment of Anastomotic Stenosis: An Unusual Complication and its Successful Surgical Management
}

\author{
Yusuf Velioglu and Ahmet Yuksel \\ Department of Cardiovascular Surgery, Abant Izzet Baysal University, Faculty of Medicine, Bolu, Turkey
}

\begin{abstract}
The incidence of iatrogenic femoral artery pseudoaneurysm (FAP) has dramatically increased due to marked increase of endovascular procedures in recent years. Once diagnosed, a prompt and optimal treatment should be done as soon as possible to avoid potential complications like thromboembolism, ischemia, rupture and bleeding. There are several treatment options for this disorder. Among them, open surgical repair is preferred when other therapeutic options fail. Here, we present a case of a large iatrogenic femoral artery pseudoaneurysm as a rare complication of endovascular stenting for the treatment of an anastomotic stenosis of previous bypass graft, which was successfully treated with open surgery.
\end{abstract}

Key Words: Femoral artery pseudoaneurysm, Open surgical repair, Endovascular approach, Stenting.

How to cite this article: Velioglu Y, Yuksel A. An iatrogenic femoral artery pseudoaneurysm caused by endovascular stenting for the treatment of anastomotic stenosis: an unusual complication and its successful surgical management. J Coll Physicians Surg Pak 2019; 29(9):895-7.

\section{INTRODUCTION}

Although iatrogenic pseudoaneurysm is a rare complication, increased number of invasive diagnostic and therapeutic interventions has led to an increased frequency of iatrogenic pseudoaneurysms, mostly in the extremity arteries. ${ }^{1-3}$ Diagnosis of an iatrogenic pseudoaneurysm is often established with a detailed medical history and physical examination, but duplex ultrasonography is almost always needed for confirmation of the diagnosis. Following the establishment of diagnosis of a large iatrogenic pseudoaneurysm, patients should be treated immediately to avoid potential complications like thromboembolism, ischemia, hemorrhage and rupture.1,3,4

Herein, we report a case of a large iatrogenic femoral artery pseudoaneurysm (FAP) following endovascular stenting for the treatment of anastomotic stenosis of a prior synthetic bypass graft, which was treated with open surgical approach.

\section{CASE REPORT}

A 67-year man was referred to our department due to the presence of a pulsatile swelling in right inguinal region. He was hospitalised with the diagnosis of

Correspondence to: Dr. Yusuf Velioglu, Department of Cardiovascular Surgery, Abant Izzet Baysal University Faculty of Medicine, Gölköy Campus, 14280, Bolu, Turkey

E-mail: yusufvelioglu@gmail.com

Received: October 01, 2018; Revised: January 19, 2019; Accepted: March 18, 2019 hypertension, diabetes mellitus and a new-onset cerebrovascular event by the neurologist, monitored and treated at intensive care unit (ICU) for a 12-day period. His medical history revealed a previous vascular surgery, aortobifemoral bypass operation with use of bifurcated Dacron graft, which was performed 9 years ago due to the presence of aortoiliac occlusive disease. In addition to this operation, he had a history of endovascular stenting for the treatment of severe stenosis of end-to-side anastomosis between right common femoral artery and synthetic bypass graft 5 months ago. Following this endovascular intervention, a progressively enlarging swelling in right inguinal region was noted afterwards (Figure 1). He was imaged using duplex ultrasonography and digital subtraction angiography for the purpose of both definite diagnosis of FAP and determination of the dimensions and extension of pseudoaneurysm to adjacent vessels and relation with other structures. According to these imaging methods, a pseudoaneurysm formation of right common femoral artery measuring $9.5 \mathrm{~cm} \times 5 \mathrm{~cm}$ along with a $3 \mathrm{~cm}$ fusiform aneurysmatic dilatation of left common femoral artery was revealed (Figure 2), and it was decided to perform an open surgical repair of right FAP as the most appropriate treatment option due to the presence of high risk of rupture of pseudoaneurysm and massive bleeding. Informed consent was obtained from the patient before surgery. He was operated in supine position under general anesthesia. A combined abdominal-thigh incision, which was started at right anterior axillary line and directed toward the angle between the lateral border 


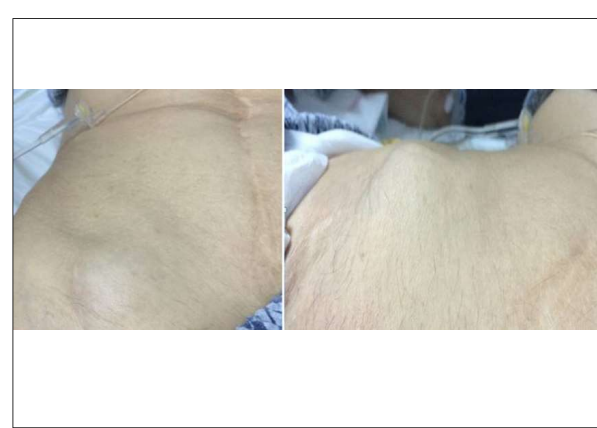

Figure 1: Preoperative view of right femoral artery pseudoaneurysm.

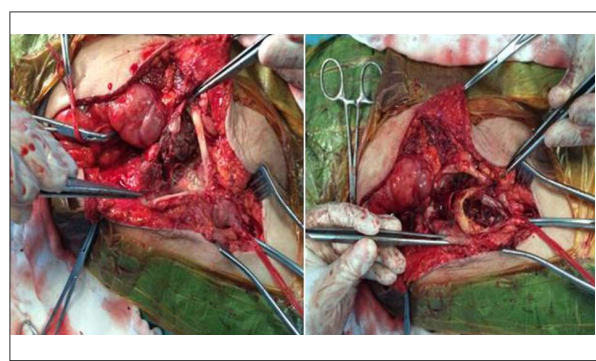

Figure 4: The view of rupture on the dacron graft and stent materials into the graft following the opening of aneurysmal sac during the operation.

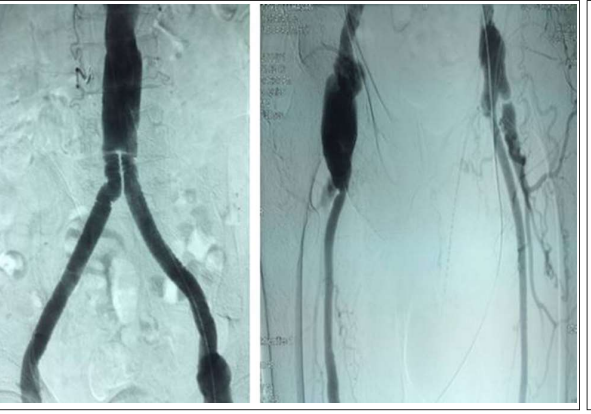

Figure 2: Angiographic view of right femoral artery pseudoaneurysm.

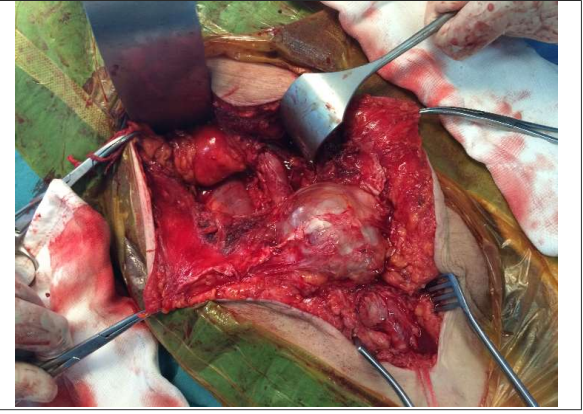

Figure 3: Intraoperative view of right femoral artery pseudoaneurysm.

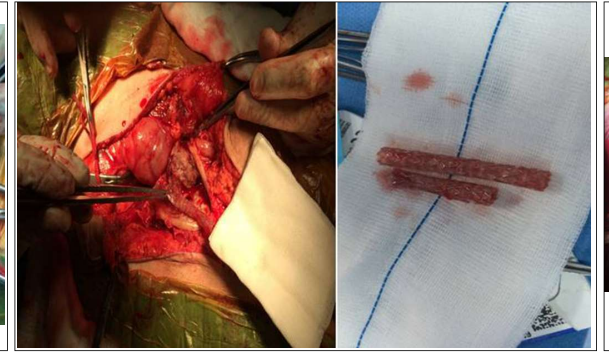

Figure 5: Removal of the stent materials from inside of the graft.

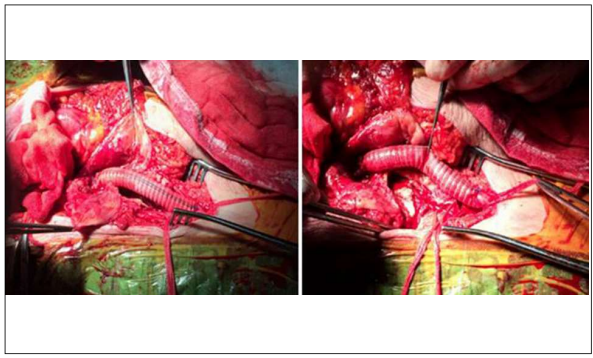

Figure 6: The view of new interposed dacron graft at the end of the operation. of the rectus abdominis and the inguinal ligament, was made. The incision was redirected distally and curved slightly with its convexity lateral to the femoral vessels. Firstly, abdominal incision was completed in a fashion of retroperitoneal approach. Retroperitoneal space was entered after the division of external oblique muscle along its fibers and transection of internal oblique and transversus muscles parallel to the inguinal ligament, hereby both right common iliac artery and bypass graft were explored and restrained using the vessel tapes. Afterwards, pseudo-aneurysmal right common femoral artery was explored after the transection of inguinal ligament (Figure 3). Once all vascular connections of pseudoaneurysm were controlled and totally clamped to provide complete hemostatic surgical site, aneurysmal sac was longitudinally opened. A rupture of the Dacron graft was observed along with visible stent materials in the graft (Figure 4). Two stent materials were removed from inside the graft (Figure 5). Primary repair of the hole on the graft was impossible, thus an approximately $7-8 \mathrm{~cm}$ segment of the graft involving the hole was excised, and a new Dacron graft (Polymaille ${ }^{\circledR} \mathrm{C}$, Perouse Medical, Ivry-le-Temple, France) was interposed between proximal and distal part of the previous graft by using end-to-end anastomosis technique to maintain sufficient blood flow toward the limb (Figure 6). After new interposed graft was covered by aneurysmal sac and sufficient hemostasis of hemorrhagic sites was provided, the operation was ended. Patient was transferred to ICU and closely monitored in terms of not only hemodynamic parameters but also potential postoperative complications such as bleeding and limb ischemia. However, patient died due to sepsis secondary to pneumonia and multiorgan failure 17 days after surgery.

\section{DISCUSSION}

In the contemporary medicine era, frequency of peripheral arterial pseudoaneurysms has dramatically increased because of significant increase of endo-vascular diagnostic and therapeutic procedures as well as penetrating or iatrogenic injuries of peripheral arteries over the last two decades. Incidence of lower extremity peripheral artery pseudoaneurysms is higher than upper extremity iatrogenic pseudoaneurysms, and the most common site of lower extremity pseudoaneurysms is femoral artery, since it is the most common vascular access site. ${ }^{1-3}$ Although the reported incidence of iatrogenic FAP after percutaneous access varies widely in the literature, its expected acceptable rate is $<0.2 \%$, according to some society guidelines. ${ }^{5}$ When a diagnosis of a large FAP is established, the most appropriate treatment modality should be selected and performed as earlier as possible. Prompt diagnostic and accurate therapeutic approach of the large iatrogenic FAPs is very important since they have the potential of serious complications like rupture, massive bleeding and limb ischemia. ${ }^{1-4}$

Various therapeutic options have been developed for the treatment of FAP. They include duplex ultrasoundguided compression, thrombin injection, endovascular treatments, like coil embolization and insertion of covered stents, and open surgical repair.6-8 Although, there are advantages and disadvantages of these therapeutic strategies, open surgery is still accepted as the gold standard treatment modality against which all 
other treatments should be compared, and is the last resort when other therapeutic options fail. Open surgical repair is preferred for iatrogenic FAP that could not or should not be treated by other methods.6,7

During last few years, endovascular treatments have increasingly gained popularity with some benefits, especially for high-risk vascular surgery patients. Nowadays, various vascular pathologies such as anastomotic stenosis after a vascular surgical procedure can be successfully treated with the percutaneous transluminal angioplasty and stenting. ${ }^{9,10}$ Although these endovascular approaches are generally associated with satisfactory results, they also have some potential risks like arterial dissection and rupture, especially in inexperienced hands. Therefore, it is essential that vascular interventionists should keep in mind these potential risks related to endovascular interventions and be meticulous when performing the procedure. For example, interventionists should not force to continue with the procedure, if they face an event that the guidewire has an obstacle and could not go forward into the vessel during the procedure. In this reported case, we witnessed the presence of rupture on previous Dacron graft as well as two stent materials in the graft. We think that a successful surgical management of this complication was obligatory in this case, since the large iatrogenic pseudoaneurysm could have ruptured if it had not been surgically treated, and the patient could have died due to massive blood loss.

In conclusion, it should be emphasised that early and accurate open surgical approach is still the cornerstone of treatment in such cases. Additionally, it should be kept in mind that despite several advantages of endovascular treatment methods, they have some risks related to these methods as well, and practitioners must be very careful and rigorous when they perform endo-vascular interventions.

\section{PATIENT'S CONSENT:}

Informed consent was obtained from the patient before surgery.

\section{CONFLICT OF INTEREST:}

Authors declared no conflict of interest.

\section{AUTHORS' CONTRIBUTION:}

Both authors have substantially contributed to the conception design, analysis, and interpretation of data for the work; drafting the work, and are to be accountable for all aspects of the work in ensuring that questions related to the accuracy or integrity of any part of the work are appropriately investigated and resolved.

\section{REFERENCES}

1. Perler BA. Surgical treatment of femoral pseudoaneurysm following cardiac catheterization. Cardiovasc Surg 1993; 1: 118-21.

2. Kirali K, Güler M, Mansuroglu D. Pseudoaneurysms of extremity arteries and treatments. Turk Gogus Kalp Dama 2000; 8:802-4.

3. Yuksel A, Nas OF, Kan II, Tok M, Erdogan C. Percutaneous coil embolization for the treatment of a giant brachial artery pseudoaneurym in a child. Ann Vasc Surg 2017; 45:266.e5-266.e8.

4. Ahmad F, Turner SA, Torrie P, Gibson M. latrogenic femoral artery pseudoaneurysms -- a review of current methods of diagnosis and treatment. Clin Radiol 2008; 63:1310-6.

5. Stone PA, Campbell JE, AbuRahma AF. Femoral pseudoaneurysms after percutaneous access. J Vasc Surg 2014; 60:1359-66.

6. Hashemi Fard O. latrogenic femoral artery pseudoaneurysm (review of treatment options). ARYA Atheroscler 2010; 6:74-7.

7. Mansour MA, Gorsuch JM. Diagnosis and management of pseudoaneurysms. Perspect Vasc Surg Endovasc Ther 2007; 19:58-64.

8. Xiong J, Liu M, Guo W, Liu X, Yin T, Jia X, et al. A retrospective study on endovascular management of iatrogenic vascular injuries. Vascular 2012; 20:65-71.

9. Lin $\mathrm{CH}$, Chen YY, Chua CH, Lu MJ. Endovascular stent-graft treatment for graft-vein anastomotic stenosis in haemodialysis patients with arteriovenous grafts. Vasa 2015; 44:466-72.

10. Eisenberg JA, Calligaro KD, Kolakowski S, Doerr KJ, Bennett S, Murtha $\mathrm{K}$, et al. Is balloon angioplasty of peri-anastomotic stenoses of failing peripheral arterial bypasses worthwhile? Vasc Endovascular Surg 2009; 43:346-51. 